\title{
Impact of type 2 diabetes mellitus on short- and long-term mortality after coronary artery bypass surgery
}

\author{
Alexander Kogan ${ }^{1,2,3^{*}}$, Eilon Ram¹,3, Shany Levin ${ }^{1}$, Enrique Z. Fisman ${ }^{3}$, Alexander Tenenbaum³ ${ }^{3}$ Ehud Raanani ${ }^{1,3}$ \\ and Leonid Sternik ${ }^{1,3}$
}

\begin{abstract}
Background: Type 2 diabetes mellitus (DM) is a frequent co-morbidity among patients undergoing coronary artery bypass grafting (CABG) surgery. The aim of this study was to evaluate the impact of DM on the early- and long-term outcomes of patients who underwent isolated CABG.

Methods: We performed an observational cohort study in a large tertiary medical center over a period of 11 years. All data from patients who had undergone isolated CABG surgery between 2004 and 2014 were obtained from our departmental database. The study population included 2766 patients who were divided into two groups: Group I (1553 non-diabetic patients), and Group II (1213 patients suffering from type 2 DM). Group II patients were then divided into two subgroups: subgroup IIA (981 patients treated with oral antihyperglycemic medications) and subgroup IIB (232 insulin-treated patients with or without additional oral antihyperglycemic drugs). In-hospital, 1-, 3-, 5and 10-year mortality outcome variables were evaluated. Mean follow-up was $97 \pm 41$ months.
\end{abstract}

Results: In-hospital mortality was similar between Group I and Group II patients (1.87\% vs. $2.31 \%, p=0.422)$ and between the subgroups IIA and IIB (2.14\% vs. 3.02\%, $p=0.464)$. Long-term mortality (1, 3, 5 and 10 years) was higher in Group II (DM type 2) compared with Group I (non-diabetic patients) (5.3\% vs. 3.6\%, p=0.038; 9.3\% vs. 5.6\%, $p<0.001 ; 15.3 \%$ vs. $9.3 \%, p<0.001$ and $47.3 \%$ vs. $29.6 \% p<0.001)$. Kaplan-Meier analysis demonstrated that all-cause mortality was higher in Group II compared with Group I $(p<0.001)$ and in subgroup IIB compared with subgroup IIA $(p=0.001)$. Multivariable analysis showed that DM increased the mortality hazard by twofold, and among diabetic patients, insulin treatment increased the mortality hazard by twofold.

Conclusions: Diabetic and non-diabetic patients have similar in-hospital mortality rates. Survival rates of diabetic patients start to deteriorate 3 year after surgery. Type $2 \mathrm{DM}$ is an independent predictor for long-term mortality after isolated CABG surgery. Mortality is even higher when the diabetes treatment strategy included insulin.

Keywords: Diabetes mellitus, Coronary artery bypass grafting, Revascularization, Insulin

\footnotetext{
*Correspondence: alexanderkogan140@hotmail.com;

Alexander.Kogan@sheba.health.gov.il

${ }^{1}$ Department of Cardiac Surgery, Sheba Medical Center, Tel Hashomer, Affiliated to the Sackler School of Medicine, Tel Aviv University, 52621 Tel

Aviv, Israel

Full list of author information is available at the end of the article
} 


\section{Introduction}

Diabetes mellitus (DM) doubles the risk of cardiovascular disease [1] and about $75 \%$ of deaths in diabetic patients are due to coronary artery disease [2]. Studies performed during the 1980's and 90's demonstrated increasing short- [3] and long-term mortality in diabetic patients undergoing $\mathrm{CABG}$ compared with non-diabetic patients $[4,5]$. However, more recently, reports have shown a significant reduction in mortality among patients with diabetes [6]. The aim of the current study was to investigate the impact of DM type 2 on short- and long-term mortality. The study was conducted on a large cohort of patients undergoing CABG.

\section{Methods}

The study was approved by the Sheba Medical Center Institutional Ethical Committee (Protocol No 4257). The requirement for informed consent was waived because of the retrospective nature of the study. We performed a retrospective, observational study that included prospectively-collected data from consecutive patients who had undergone a first isolated CABG at a large tertiary university hospital over an 11-year period, between 01.04.2004 and 31.03.2015. Patients were divided into two groups: Group I (non-diabetic patients), and Group II (patients suffering from type $2 \mathrm{DM}$ ). DM type 2 was defined according to the American Diabetes Association as: (a) hemoglobin $\mathrm{A} 1 \mathrm{C} \geq 6.5 \%$; (b) fasting plasma glucose levels $\geq 126 \mathrm{mg} /$ day; (c) classic symptoms of hyperglycemia or a hyperglycemic crisis, a random plasma glucose level $\geq 200 \mathrm{mg} / \mathrm{dL}$ (11.1 mmol/L) [7]; or (d) currently on pharmacologic treatment (oral antihyperglycemic drugs and/or insulin). Group II patients were divided into two subgroups: subgroup IIA, treated only with oral antihyperglycemics and subgroup IIB, treated with insulin or a combination of oral antihyperglycemic drugs and insulin.

Using non-identifiable patient data from our department's database, we evaluated the following variables: gender, age, chronic obstructive pulmonary disease, congestive heart failure [New York Heart Association (NYHA) functional class], DM, dialysis-dependent renal failure, peripheral vascular disease, a previous cardiovascular accident (CVA)/transient ischemic attack (TIA), systemic and pulmonary hypertension, left ventricular function, priority of surgery (elective, urgent, or emergent), and logistic EuroSCORE I. Perioperative variables included using left and right internal mammary arteries, the number of anastomosis, time of cross-clamping and duration of cardiopulmonary bypass.

After surgery all patients were admitted to the intensive care unit (ICU) directly from the operating room. After discharge from the ICU, patients were transferred either to a step-down unit or directly to the floor, from where they were discharged either to their home or to a rehabilitation facility. In the operating room and in the ICU, patients from both groups received intravenous continuous infusion of regular insulin according to the Society of Thoracic Surgeons practice guideline series [8]. After discharge from the ICU, patients from Group I (nondiabetic) did not receive insulin or any other hypoglycemic medication, while patients from Group II continued to receive preoperative antiglycemic treatment (per oral drugs and insulin), as soon as they began to eat. We evaluated the following outcome variables: in-hospital, 1-, 3-, 5- and 10-year mortality. Mortality was ascertained from the Israeli Ministry of Interior Population Register. Mean follow-up was $98 \pm 41$ months and completed for all patients.

Throughout the study no major changes in hospital policy, surgical or anesthesiological techniques were introduced. All patients received standardized anesthesia.

\section{Database management and statistical analysis}

At discharge, all patient data were checked, corrected and entered into a database. Descriptive statistics were used to summarize data, and numerical data were expressed as means (SD). Normality of the distribution of continuous data variables was analyzed using the Kolmogorov-Smirnov test. Since not all numerical data were distributed normally, Mann-Whitney U-tests were used to evaluate differences between groups. Differences between the frequencies of categorical variables were also estimated using Fisher's exact test. All outcome variables were compared between whole groups of patients.

Variables that had a possible influence on patient mortality (univariate predictors) were evaluated using Fisher's exact test. Suspected predictors for mortality by univariable analysis were analyzed by a multivariable logistic regression analysis in order to find independent predictors of mortality. The variables included in the final model among the entire cohort were: DM, Euroscore, NYHA functional class, and hyperlipidemia. The variables included in the final model among the diabetic patients were: insulin therapy, Euroscore, NYHA functional class, and hyperlipidemia. $\mathrm{p}$ values of 0.05 and less were considered as statistically significant. All statistical analyses were performed using SPSS 11.5 for Windows.

\section{Results}

\section{Baseline characteristics}

During the 11-year study period, 2972 patients underwent isolated CABG, of whom 36 patients were excluded from the study due to incomplete data, and a further 170 patients were excluded since they suffered from DM type 1. The study population included 2766 patients (Table 1 ). Group I (non-diabetic patients), comprised 1553 
Table 1 Patients' data (Groups I and II)

\begin{tabular}{|c|c|c|c|}
\hline & $\begin{array}{l}\text { Non-DM Group I } \\
\text { No. of patients (1553) }\end{array}$ & $\begin{array}{l}\text { DM Group II } \\
\text { No. of patients (1213) }\end{array}$ & $p$ value \\
\hline Age (years) & $63 \pm 11$ & $65 \pm 10$ & 0.000 \\
\hline Males & $1308(84 \%)$ & $947(78 \%)$ & 0.000 \\
\hline Elective & $978(63 \%)$ & $788(65 \%)$ & 0.378 \\
\hline NYHA FC III-IV & $373(20 \%)$ & $376(27 \%)$ & 0.001 \\
\hline Previous operation & $32(2 \%)$ & $37(3 \%)$ & 0.110 \\
\hline Ejection fraction (\%) & $51 \pm 11$ & $50 \pm 11$ & 0.001 \\
\hline Logistic EuroSCORE & $5.6 \pm 8.2$ & $6.4 \pm 9.6$ & 0.020 \\
\hline Hypertension & 1065 (69\%) & $1052(87 \%)$ & 0.000 \\
\hline COPD & $70(4 \%)$ & $61(5 \%)$ & 0.529 \\
\hline Dialysis & $17(1 \%)$ & $24(2 \%)$ & 0.059 \\
\hline Hyperlipidemia & 1097 (71\%) & 1019 (84\%) & 0.000 \\
\hline PVD & $111(7 \%)$ & $185(15 \%)$ & 0.000 \\
\hline CVA/TIA & $100(6 \%)$ & $130(11 \%)$ & 0.000 \\
\hline Pulmonary hypertension & $3(0.2 \%)$ & $16(1 \%)$ & 0.001 \\
\hline Arrhythmia & $8(0.5 \%)$ & $6(0.5 \%)$ & 1.000 \\
\hline LIMA & 1509 (97\%) & 1171 (97\%) & 0.378 \\
\hline No mammary & $26(2 \%)$ & $28(2 \%)$ & 1.000 \\
\hline Double mammary & 781 (50\%) & $468(39 \%)$ & 0.000 \\
\hline Number of grafts & $3.1 \pm 1.1$ & $3.1 \pm 1.0$ & 0.411 \\
\hline Bypass & $80 \pm 27$ & $82 \pm 42$ & 0.133 \\
\hline Clamp & $56 \pm 20$ & $56 \pm 29$ & 0.701 \\
\hline Mini invasive & $33(2 \%)$ & $21(2 \%)$ & 0.491 \\
\hline
\end{tabular}

DM Diabetes mellitus, NYHA FC New York Heart Association functional class, COPD chronic obstruction pulmonary disease, $P V D$ peripheral vascular disease, CVA cerebral vascular accident, TIA transient ischemic attack, LIMA left internal mammary artery

patients, and Group II (patients suffering from DM type 2), comprised 1213 patients. Of them, 981 patients were treated with oral antihyperglycemic medications (Group IIA) and 232 patients were treated with insulin (Group IIB) (Table 2). Compared with the non-diabetic group, the diabetic group of patients were older, more frequently women, had a higher mean logistic EuroSCORE, and had a higher prevalence of systemic and pulmonary hypertension, peripheral vascular disease and previous CVA.

\section{Early outcomes}

Overall in-hospital mortality was similar between Groups I and II: $1.87 \%$ vs. $2.31 \%, \mathrm{p}=0.422$, and between subgroups IIA and IIB: $2.14 \%$ vs. $3.01 \%, p=0.464$. Other in-hospital major events were similar between Groups I and II, such as CVA (0.3\% vs. $0.5 \%, p=0.350)$, use of intra-aortic balloon pump ( $5 \%$ vs. $5 \%, \mathrm{p}=0.859)$ and renal replacement therapy $(0.7 \%$ vs. $1.5 \%, \mathrm{p}=0.059)$. Major events were also similar between the non-insulin dependent and insulin-dependent DM patients: CVA $(0.5 \%$ vs. $0.4 \%, \mathrm{p}=1.000)$, use of intra-aortic balloon pump ( $5 \%$ vs. $6 \%, \mathrm{p}=0.239)$ and renal replacement therapy $(1 \%$ vs. $2 \%, p=0.364)$. Group II compared to Group I, and Group IIB compared to Group IIA experienced a significantly higher rate of prolonged mechanical ventilation time (over $72 \mathrm{~h}$ ) (5.6\% vs. 3.1\%, $\mathrm{p}=0.001$ and $9.7 \%$ vs. $4.7 \%, \mathrm{p}=0.006),>7$ days in the ICU $(5.7 \%$ vs. $2.7 \%$, $\mathrm{p}<0.001$ and $9.7 \%$ vs. $4.8 \%, \mathrm{p}=0.007)$ and a significantly longer hospital duration $(7.6 \pm 7.9$ vs. $6.7 \pm 5.2, \mathrm{p}<0.001$ and $9 \pm 8$ vs. $7 \pm 8, p=0.042$ ).

\section{Follow-up mortality}

Long-term mortality (1, 3, 5 and 10 years) was higher in Group II (DM type 2) compared with Group I (nondiabetic patients) $(5.3 \%$ vs. $3.6 \%, p=0.038 ; 9.3 \%$ vs. $5.6 \%$, $\mathrm{p}<0.001 ; 15.3 \%$ vs. $9.3 \%, \mathrm{p}<0.001$ and $47.3 \%$ vs. $29.6 \%$, $\mathrm{p}<0.001$ ) (Fig. 1; Additional file 1: Table S1). These results were also consistent among the subgroup of patients with NYHA functional class I-II and III-IV (Additional file 2: Figure S1 and Additional file 3: Figure S2).

Furthermore, long-term mortality was higher in subgroup IIB (insulin-treated patients) compared to subgroup IIA (non-insulin treated patients) with 1-, 3-, 5 - and 10 -year mortality rates of $6.5 \%$ vs. $5 \%, \mathrm{p}=0.413$; $14.2 \%$ vs. $8.2 \%, \mathrm{p}=0.008 ; 22.1 \%$ vs. $13.6 \%, \mathrm{p}=0.002$ and $59.3 \%$ vs. $44.3 \%, \mathrm{p}=0.002$ (Fig. 2; Additional file 1: Table S2). These results were also consistent among the subgroup of patients with NYHA functional class I-II 
Table 2 Patients' data (subgroups IIA and IIB)

\begin{tabular}{|c|c|c|c|}
\hline & $\begin{array}{l}\text { Non-insulin } \\
\text { No. of patients }=981\end{array}$ & $\begin{array}{l}\text { Insulin } \\
\text { No. of patients }=232\end{array}$ & $\mathrm{p}$ value \\
\hline Age (years) & $65 \pm 10$ & $64 \pm 10$ & 0.023 \\
\hline Males & 775 (79\%) & $172(74 \%)$ & 0.113 \\
\hline Elective & $627(65 \%)$ & $149(65 \%)$ & 1.000 \\
\hline NYHA FC III-IV & $284(26 \%)$ & $88(31 \%)$ & 0.003 \\
\hline Previous operation & $28(3 \%)$ & $9(4 \%)$ & 0.399 \\
\hline Ejection fraction (\%) & $51 \pm 11$ & $47 \pm 12$ & 0.000 \\
\hline Logistic EuroSCORE & $6 \pm 9$ & $8 \pm 11$ & 0.012 \\
\hline Hypertension & $847(86 \%)$ & $205(88 \%)$ & 0.453 \\
\hline COPD & $51(5 \%)$ & $10(4 \%)$ & 0.738 \\
\hline Dialysis & $12(1 \%)$ & $12(5 \%)$ & 0.001 \\
\hline Hyperlipidemia & $818(83 \%)$ & $201(87 \%)$ & 0.273 \\
\hline PVD & $125(13 \%)$ & $60(26 \%)$ & 0.000 \\
\hline CVA/TIA & $106(11 \%)$ & $24(10 \%)$ & 0.906 \\
\hline Pulmonary hypertension & $10(1 \%)$ & $6(3 \%)$ & 0.099 \\
\hline Arrhythmia & $2(0.2 \%)$ & $4(2 \%)$ & 0.014 \\
\hline LIMA & 949 (97\%) & $222(96 \%)$ & 0.426 \\
\hline Double mammary & $396(40 \%)$ & $72(31 \%)$ & 0.032 \\
\hline Number of grafts & $3 \pm 1$ & $3 \pm 1$ & 0.231 \\
\hline Bypass & $83 \pm 42$ & $81 \pm 40$ & 0.471 \\
\hline Clamp & $57 \pm 31$ & $53 \pm 17$ & 0.014 \\
\hline Mini invasive & $18(2 \%)$ & $3(1 \%)$ & 0.781 \\
\hline
\end{tabular}

NYHA FC New York Heart Association functional class, COPD chronic obstruction pulmonary disease, $P V D$ peripheral vascular disease, CVA cerebral vascular accident, TIA transient ischemic attack, LIMA left internal mammary artery

and III-IV (Additional file 4: Figure S3 and Additional file 5: Figure S4).

Multivariable analysis demonstrated that predictors for 10 years' mortality were higher on EuroSCORE (HR $1.3895 \%$ CI 1.31-1.46, $\mathrm{p}<0.001$ ), hyperlipidemia (HR 1.39 95\% CI 1.02-1.92, $\mathrm{p}=0.037)$ and DM (HR $2.0895 \%$ CI 1.57-2.74, $\mathrm{p}<0.001)$. Among the diabetic patients, predictors for 10 years' mortality were higher on EuroSCORE (HR 1.37 95\% CI 1.3-1.45, p <0.001), hyperlipidemia (HR 1.45 95\% CI 1.06-1.97, $\mathrm{p}=0.021$ ) and insulin treatment (HR 2.11 95\% CI 1.34-3.3, $\mathrm{p}=0.001$ ). Although higher NYHA functional class was a risk factor for late mortality by univariable analysis $(p=0.001)$, it was not associated with late mortality after adjustment for confounders by multivariable analysis, both in the entire cohort $(\mathrm{p}=0.834)$ and among the diabetic patients $(\mathrm{p}=0.831)$.

\section{Discussion}

Our study investigated the impact of DM type 2 on inhospital and long-term mortality in patients after their first isolated CABG. First, we found that among patients undergoing $\mathrm{CABG}$, diabetic and non-diabetic patients had similar in-hospital mortality. Second, our principal finding was that the long-term mortality of diabetic patients was higher than that of non-diabetic patients. Furthermore, mortality was even higher when the diabetic treatment strategy included insulin compared to treatment without insulin. Macrovascular disease (coronary artery disease, stroke, and peripheral vascular disease) was responsible for the majority of morbidity and mortality associated with type 2 DM [9]. It should be pointed out that incident diabetes in adults is associated with a substantial risk for mortality, especially in younger adults [10], and in the presence of coronary artery disease (CAD) early revascularization is overwhelmingly important, since a deferred revascularization procedure in patients with and without DM shows that the former are associated with a significantly higher target lesion failure rate [11].

The impact of diabetes on short-term mortality after CABG was insignificant. Abizaid et al. [12] reported similar in-hospital and 1-year mortality rates for diabetic and non-diabetic patients: $2.1 \%$ vs. $1.2 \%$ and $3.1 \%$ vs. $2.8 \%$. In addition, Marui et al. [13] found no differences in 30-day and 1-year mortality between diabetic and non-diabetic patients: $0.9 \%$ vs. $1.2 \%$ and $4.4 \%$ vs. $4.5 \%$. Carson et al. [3] reported a 30 -day mortality rate of $3.7 \%$ in patients with DM and $2.7 \%$ in those without DM. While Li et al. [14] reported similar post-CABG mortality rates for 
non-diabetic and diabetic patients treated with oral antihyperglycemic medication ( $1.88 \%$ vs. $2.01 \%)$, they showed a significant increase in mortality in a subgroup of diabetic patients treated with insulin (3.08\%). ZalewskaAdamiec et al. [15] found no differences in 30-day, 1 - and 2 -year mortality rates $(11.6 \%$ vs. $11.1 \%)$ in diabetic and non-diabetic patients with left main coronary artery disease. Whang et al. [16] found no differences in 2 -year mortality rates between diabetic and non-diabetic patients: $26 \%$ vs. $24 \%$, and concluded that diabetes was not a predictor of mortality after CABG among patients with left ventricular dysfunction. Although diabetic patients in our series were older and had more comorbidities, differences in early mortality did not reach statistical significance. We report here that in-hospital mortality among diabetic $(\mathrm{N}=1553)$ and non- diabetic patients $(\mathrm{N}=1213)$, was $2.3 \%$ and $1.9 \%$. With these rates of mortality in a group the size of ours, we achieved a power of $13 \%$ to detect differences between the groups. Even if we would have reached the statistical significance, the clinical implications of these differences would have been questionable, since it is obvious that the most important impact of DM is on long-term results. In the non-insulin compared with the insulin-treated subgroup of patients, mortality was $2.14 \%$ vs. $3.01 \%, p=0.464$, and at 1 year, mortality was $5 \%$ vs. $6.5 \%, p=0.413$. In this context, it should be stressed that among hospitalized heart failure patients with no pre-existing DM there is a linear relationship between admission blood glucose and long-term mortality, whereas among patients with DM only an admission level of $>200 \mathrm{mg} / \mathrm{dL}$ is associated with increased mortality risk [17].

However, the impact of diabetes on long-term mortality after CABG has been controversial. Marui et al. [13] reported an increase in 3- and 5-years' mortality in diabetic compared to non-diabetic patients, $11 \%$ vs. 9.7\% and $19.6 \%$ vs. $16.2 \%$. Mohamadi et al. [18] investigated only cardiac-specific survival rates, but not all-cause mortality, and postulated that DM type 2 diabetes is not an independent predictor of late cardiac death 6 years after CABG. Furthermore, Onuma et al. [19] reported slightly increasing mortality rates in diabetic compared with non-diabetic patients 5 years after CABG: $8.6 \%$ vs. $7.1 \%$. Kappetein et al. [20] also investigated 5 years' mortality after CABG and reported non-significant differences between diabetic and non-diabetic patients: $12.9 \%$ vs. $10.9 \%$. However, Koshizaka et al. [21] reported significant differences in 5 years' mortality: $15.5 \%$ vs. $8.5 \%$. Wit et al. [22] reported significantly higher 3-year mortality rates in patients with insulin-treated compared with noninsulin-treated DM (16.7\% vs. $8.7 \%)$ and non-diabetic patients (6.3\%). In their systematic reviews and metaanalyses Bundhun et al. [23] postulated that diabetes is associated with increased long-term mortality after CABG, while CABG was associated with significantly lower long-term adverse clinical outcomes compared to percutaneous coronary intervention (PCI) in patients with insulin-treated type $2 \mathrm{DM}$ [24].

While in the general population DM is associated with excess mortality, compared with the general population without DM, with a hazard ratio of 1.15 at 5-years [25], we reported a greater impact of DM on patients who underwent CABG (HR of 1.68 at 5 years). Although we have no data regarding the cause of death, myocardial infarction, and graft patency during the follow-up period, we assume that this higher impact of DM in our cohort, compared to the natural history of DM in the general population, is due to accelerated CAD, based on previous studies that support this theory [26].

In our report the 5-year mortality rate was 15.3\% among diabetic patients and $9.3 \%$ among non-diabetic patients. Although we did not compare our results to a percutaneous approach, based on previous reports among diabetic and non-diabetic patients with multivessel CAD who were treated by PCI, our results were somewhat better. Among diabetic patients, Farkouh et al. [27] reported 5-year mortality rates of $26.6 \%$ in the PCI group. Contini et al. [28] reported a 5-year mortality rate of $24.5 \%$ in diabetic patients who underwent PCI. Kappetein et al. [20], throughout a 5-year follow-up, showed that PCI revealed a mortality rate of $19.5 \%$ in diabetic patients, and $12.0 \%$ in non-diabetic patients.

Only $18.5 \%$ of the patients in the current study were female, as reported in previous studies where the patients were also predominantly male $[13,18,19]$. The explanation for this observation could be that cardiovascular disease develops in an older age in females than in males, and older age increases the surgical risk. The differences in clinical presentation in women lead to less aggressive treatment strategies with less referral for surgical revascularization [29].

We reported that 1213 out of the 2766 patients (44\%) who underwent isolated CABG in our Institute had diabetes, more than the average in previous reports [18-20]. Blumenfeld et al. [30] reported that in Israel, the threshold of patient referral for surgical revascularization has risen in the last two decades, and that those patients have more comorbidities than in the past. Since the advantage of CABG over PCI is seen mostly in patients with complex CAD, such as left-main stenosis or high SYNTAX score, and in diabetic patients, the characteristics of patients who are referred to CABG has changed during the last decade toward patients with a more complex anatomy and more diabetes. Recent reports based on National Registries have shown that $43-49 \%$ of the patients who were referred to CABG in Israel had 


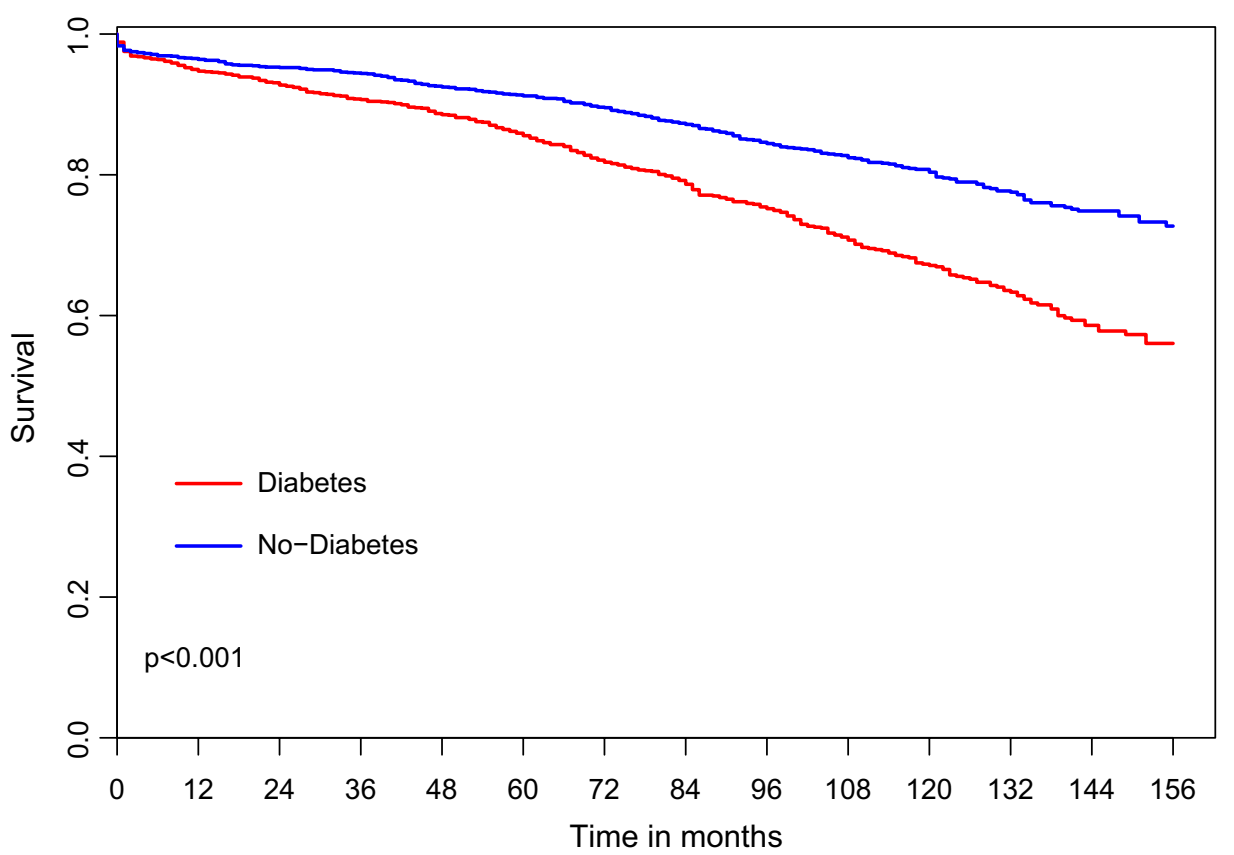

$\begin{array}{rrrrrrrrrrrrrrr}\text { \# at risk } \\ \text { Diabetes } & 1213 & 1152 & 1129 & 1101 & 1075 & 969 & 829 & 728 & 602 & 493 & 365 & 262 & 157 & 60 \\ \text { No-Diabetes } & 1553 & 1499 & 1480 & 1467 & 1438 & 1326 & 1181 & 1062 & 906 & 776 & 603 & 444 & 267 & 111\end{array}$

Fig. 1 Survival rate by DM groups. DM Diabetes mellitus

diabetes [31, 32]. The current study is based on the population of a tertial referral center in Israel, and thus our report is consistent with real-life situations in Israel.

Diabetes mellitus is a chief cause of heart failure, either secondary to CAD or secondary to diabetic cardiomyopathy [33]. In general, insulin-dependent diabetic patients have more comorbidities than non-insulin dependent diabetic patients. Although the presence of insulin treatment is indeed a marker for more advanced disease, its underlying biological mechanism has not been fully elucidated. It may be related to the impact of a procoagulant imbalance, chronic exposure to high glucose levels, and direct effects of hyperinsulinemia. Interestingly, endogenous hyperinsulinemia has been associated with increased long-term mortality following myocardial infarction in patients without diabetes [34]. Further studies are needed to examine whether insulin-dependent diabetic patients should be included in risk stratification algorithms for patients who undergo CABG.

\section{Limitations}

There are a few limitations in our study. First, while it is retrospective in design, data were collected prospectively and recorded in a well-defined database. Second, our study was conducted in a single-center cardiac surgery department. Third, we had no information regarding the main cause of death, the rate of cardiac events and data regarding graft patency during the follow-up period. Analysis of cardiac events could reinforce the conclusion that DM provides less favorable results after CABG. The lack of information regarding the main cause of death weakens the conclusions of this study.

\section{Conclusions}

DM type-2 is an independent predictor of long-term mortality after CABG surgery. Mortality rates increased significantly when the diabetic treatment strategy included insulin. The high-risk population of insulindependent DM may require specific and/or more intense cardiovascular protective therapies after CABG. Further studies are needed to examine whether novel interventions, such as GLP-1 analogues or SGLT2 inhibitors, can improve their long-term outcomes. Since the current study is underpowered to detect reduced early survival in diabetic patients a larger study is warranted in order to reach significant differences in early mortality, which would enable us to conclude that DM may impact early results after CABG. 


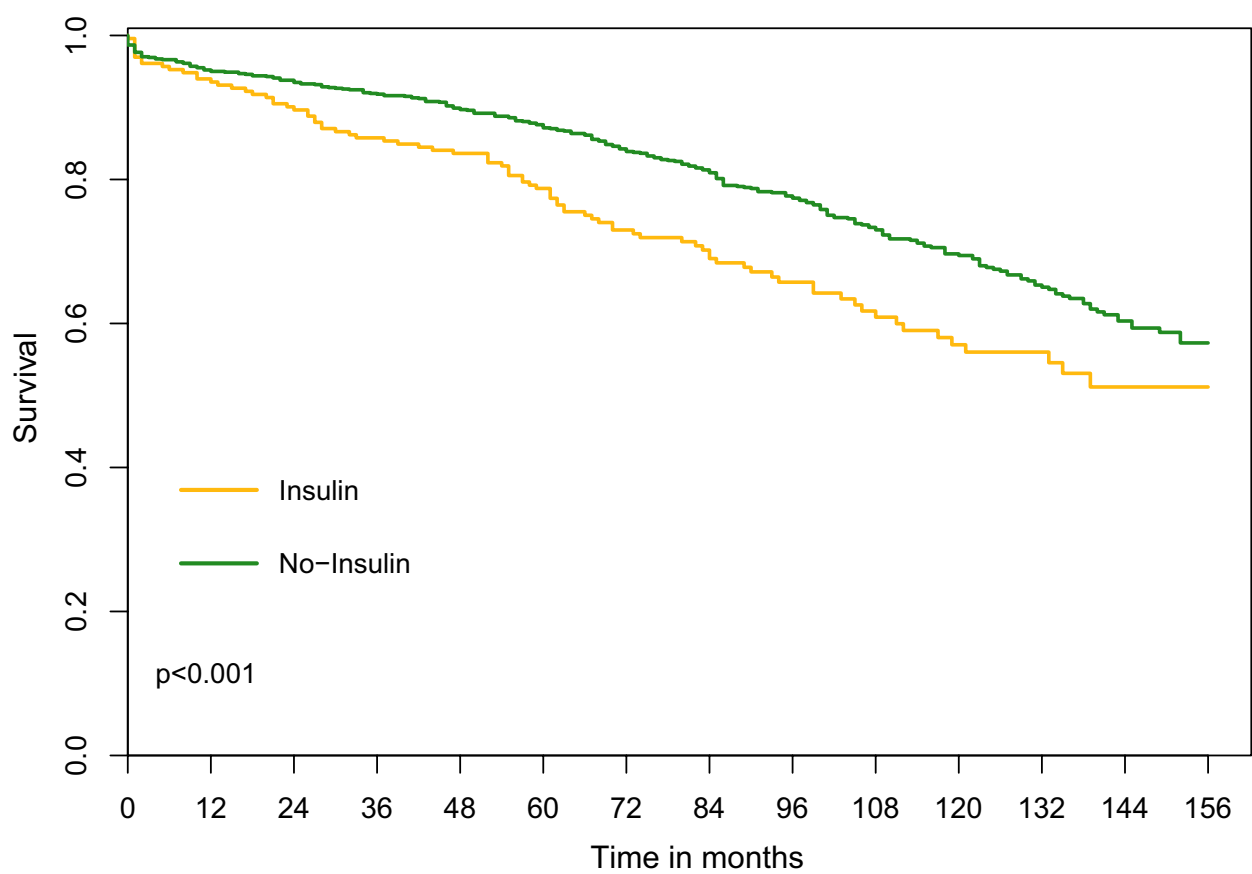

$\begin{array}{rllllllllllllll}\text { \# at risk } & & & & & & & & & & & & & \\ \text { Insulin } & 232 & 218 & 209 & 199 & 194 & 173 & 139 & 119 & 90 & 72 & 57 & 40 & 23 & 9 \\ \text { No-Insulin } & 981 & 934 & 920 & 902 & 881 & 796 & 690 & 609 & 512 & 421 & 308 & 222 & 134 & 51\end{array}$

Fig. 2 Survival rate in the DM group by insulin treatment. DM Diabetes mellitus

\section{Additional files}

Additional file 1: Table S1. Life table for mortality in the entire cohort by patients with and without diabetes mellitus. A. Patients with diabetes mellitus. B. Patients without diabetes mellitus. Table S2. Life table for mortality among diabetic patients on insulin. A. Patients treated by insulin. B. Patients without insulin treatment.

Additional file 2: Figure S1. Survival rate by DM groups among patients with NYHA functional class I-II. DM = Diabetes mellitus; NYHA = NewYork Heart Association.

Additional file 3: Figure S2. Survival rate by DM groups among patients with NYHA functional class III-IV. DM = Diabetes mellitus; NYHA = NewYork Heart Association.

Additional file 4: Figure S3. Survival rate in the DM group receiving insulin treatment among patients with NYHA functional class I-II. DM = Diabetes mellitus; NYHA = New-York Heart Association.

Additional file 5: Figure S4. Survival rate in the DM group receiving insulin treatment among patients with NYHA functional class III-IV. DM = Diabetes mellitus; NYHA = New-York Heart Association.

\section{Abbreviations}

CABG: coronary artery by-pass graft; CAD: coronary artery disease; CVA: cerebrovascular accident; DM: diabetes mellitus; ICU: intensive care unit; PCI: percutaneous coronary intervention; TIA: transient ischemic attack.

\section{Authors' contributions}

AK: wrote the research project and the full manuscript. ER: study revision and editing. SL: data collection and interpretation. EZF, AT: study revision and editing. ER: study revision. LS: wrote the research project and study revision. All authors read and approved the final manuscript.

\section{Author details}

${ }^{1}$ Department of Cardiac Surgery, Sheba Medical Center, Tel Hashomer, Affiliated to the Sackler School of Medicine, Tel Aviv University, 52621 Tel Aviv, Israel. ${ }^{2}$ Cardiac Surgery Intensive Care Unit, Sheba Medical Center, Tel Hashomer, Affiliated to the Sackler School of Medicine, Tel Aviv University, Tel Aviv, Israel. ${ }^{3}$ Tel Aviv University, Tel Aviv, Israel.

\section{Acknowledgements}

Not applicable.

\section{Competing interests}

The authors declare that they have no competing interests.

\section{Availability of data and materials}

Data collected from a departmental database.

\section{Consent for publication}

Not applicable.

Ethics approval and consent to participate

Institutional Ethical Committee (Protocol No 4257).

\section{Financial disclosures}

None to declare.

\section{Funding}

None. 


\section{Publisher's Note}

Springer Nature remains neutral with regard to jurisdictional claims in published maps and institutional affiliations.

Received: 4 November 2018 Accepted: 26 November 2018 Published online: 29 November 2018

\section{References}

1. Sarwar N, Gao P, Seshasai SR, Gobin R, Kaptoge S, Di Angelantonio E, et al. Diabetes mellitus, fasting blood glucose concentration, and risk of vascular disease: a collaborative meta-analysis of 102 prospective studies. Lancet. 2010;375:2215-22.

2. O'Gara PT, Kushner FG, Ascheim DD, Casey DE Jr, Chung MK, de Lemos JA, et al. 2013 ACCF/AHA guideline for the management of ST-elevation myocardial infarction: a report of the American College of Cardiology Foundation/American Heart Association Task Force on Practice Guidelines. Circulation. 2013;127:e362-425.

3. Carson JL, Scholz PM, Chen AY, Peterson ED, Gold J, Schneider SH. Diabetes mellitus increases short-term mortality and morbidity in patients undergoing coronary artery bypass graft surgery. J Am Coll Cardiol. 2002:40:418-23.

4. Adler DS, Goldman L, O'Neil A, Cook EF, Mudge GH Jr, Shemin RJ, et al. Long-term survival of more than 2,000 patients after coronary artery bypass grafting. Am J Cardiol. 1986;58:195-202.

5. Barsness GW, Peterson ED, Ohman EM, Nelson CL, DeLong ER, Reves JG, et al. Relationship between diabetes mellitus and long-term survival after coronary bypass and angioplasty. Circulation. 1997;96:2551-6.

6. Rawshani A, Rawshani A, Franzén S, Eliasson B, Svensson AM, Miftaraj M, et al. Mortality and cardiovascular disease in type 1 and type 2 diabetes. N Engl J Med. 2017;376:1407-18.

7. American Diabetes Association. Classification and diagnosis of diabetes. Diabetes Care. 2015;38(Suppl):S8-16.

8. Lazar HL, McDonnell M, Chipkin SR, Furnary AP, Engelman RM, Sadhu AR, Society of Thoracic Surgeons Blood Glucose Guideline Task Force, et al. The Society of Thoracic Surgeons practice guideline series: blood glucose management during adult cardiac surgery. Ann Thorac Surg. 2009:87:663-9.

9. Monteiro $P$, Gonçalves L, Providência LA. Diabetes and cardiovascular disease: the road to cardioprotection. Heart. 2005;91:1621-5.

10. Zucker I, Shohat T, Dankner R, Chodick G. New onset diabetes in adulthood is associated with a substantial risk for mortality at all ages: a population based historical cohort study with a decade-long follow-up. Cardiovasc Diabetol. 2017;16:105.

11. Kennedy MW, Kaplan E, Hermanides RS, Fabris E, Hemradj V, Koopmans PC, et al. Clinical outcomes of deferred revascularisation using fractional flow reserve in patients with and without diabetes mellitus. Cardiovasc Diabetol. 2016;15:100.

12. Abizaid A, Costa MA, Centemero M, Abizaid AS, Legrand VM, Limet RV Arterial Revascularization Therapy Study Group, et al. Clinical and economic impact of diabetes mellitus on percutaneous and surgical treatment of multivessel coronary disease patients: insights from the Arterial Revascularization Therapy Study (ARTS) trial. Circulation. 2001;104:533-8.

13. Marui A, Kimura T, Nishiwaki N, Mitsudo K, Komiya T, Hanyu M, CREDOKyoto PCI/CABG Registry Cohort-2 Investigators, et al. Five-year outcomes of percutaneous versus surgical coronary revascularization in patients with diabetes mellitus (from the CREDO-Kyoto PCI/CABG Registry Cohort-2). Am J Cardiol. 2015;115:1063-72.

14. Li Z, Amsterdam EA, Young JN, Hoegh H, Armstrong EJ. Contemporary outcomes of coronary artery bypass grafting among patients with insulin-treated and non-insulin-treated diabetes. Ann Thorac Surg. 2015;100:2262-9.

15. Zalewska-Adamiec M, Bachorzewska-Gajewska H, Malyszko J, TomaszukKazberuk A, Nowak K, Hirnle T, et al. Impact of diabetes on mortality and complications after coronary artery by-pass graft operation in patients with left main coronary artery disease. Adv Med Sci. 2014;59:250-5.

16. Whang W, Bigger JT Jr, The CABG Patch Trial Investigators and Coordinators. Diabetes and outcomes of coronary artery bypass graft surgery in patients with severe left ventricular dysfunction: results from The CABG Patch Trial database. J Am Coll Cardiol. 2000;36:1166-72.

17. Zadok OIB, Kornowski R, Goldenberg I, Klempfner R, Toledano Y, Biton Y, et al. Admission blood glucose and 10-year mortality among patients with or without pre-existing diabetes mellitus hospitalized with heart failure. Cardiovasc Diabetol. 2017;16:102.

18. Mohammadi S, Dagenais F, Mathieu P, Kingma JG, Doyle D, Lopez S, et al. Long-term impact of diabetes and its comorbidities in patients undergoing isolated primary coronary artery bypass graft surgery. Circulation. 2007;116:1220-5.

19. Onuma Y, Wykrzykowska JJ, Garg S, Vranckx P, Serruys PW, ARTS I and II Investigators. 5-Year follow-up of coronary revascularization in diabetic patients with multivessel coronary artery disease: insights from ARTS (arterial revascularization therapy study)-II and ARTS-I trials. J Am Coll Cardiol Cardiovasc Interv. 2011;4:317-23.

20. Kappetein AP, Head SJ, Morice MC, Banning AP, Serruys PW, Mohr FW, et al. Treatment of complex coronary artery disease in patients with diabetes: 5-year results comparing outcomes of bypass surgery and percutaneous coronary intervention in the SYNTAX trial. Eur J Cardiothorac Surg. 2013;43:1006-13.

21. Koshizaka M, Lopes RD, Reyes EM, Gibson CM, Schulte PJ, Hafley GE, et al. Long-term clinical and angiographic outcomes in patients with diabetes undergoing coronary artery bypass graft surgery: results from the Project of Ex-vivo Vein Graft Engineering via Transfection IV trial. Am Heart J. 2015;169:175-84.

22. Wit MA, de Mulder M, Jansen EK, Umans VA. Diabetes mellitus and its impact on long-term outcomes after coronary artery bypass graft surgery. Acta Diabetol. 2013;50:123-8.

23. Bundhun PK, Bhurtu A, Yuan J. Impact of type 2 diabetes mellitus on the long-term mortality in patients who were treated by coronary artery bypass surgery: a systematic review and meta-analysis. Medicine (Baltimore). 2017;96:e7022

24. Bundhun PK, Wu ZJ, Chen MH. Coronary artery bypass surgery compared with percutaneous coronary interventions in patients with insulin-treated type 2 diabetes mellitus: a systematic review and meta-analysis of 6 randomized controlled trials. Cardiovasc Diabetol. 2016;15:2.

25. Tancredi M, Rosengren A, Svensson AM, Kosiborod M, Pivodic A, Gudbjörnsdottir S, et al. Excess mortality among persons with type 2 diabetes. N Engl J Med. 2015;373:1720-32.

26. Lathief $S$, Inzucchi SE. Approach to diabetes management in patients with CVD. Trends Cardiovasc Med. 2016;26:165-79.

27. Farkouh ME, Domanski M, Sleeper LA, Siami FS, Dangas G, Mack M, et al. Strategies for multivessel revascularization in patients with diabetes. $\mathrm{N}$ Engl J Med. 2012;367:2375-84.

28. Contini GA, Nicolini F, Fortuna D, Pacini D, Gabbieri D, Vignali L, et al. Fiveyear outcomes of surgical or percutaneous myocardial revascularization in diabetic patients. Int J Cardiol. 2013;168:1028-33.

29. Maas AH, Appelman YE. Gender differences in coronary heart disease. Neth Heart J. 2010;18:598-602.

30. Blumenfeld O, Na'amnih W, Shapira-Daniels A, Lotan C, Shohat T, Shapira OM. Trends in coronary revascularization and ischemic heart diseaserelated mortality in Israel. J Am Heart Assoc. 2017;6:e004734.

31. Fink N, Nikolsky E, Assali A, Shapira O, Kassif Y, Barac YD, et al. Revascularization strategies and survival in patients with multi-vessel coronary artery disease. Ann Thorac Surg. 2018. https://doi.org/10.1016/j.athoracsur 2018.07.070.

32. Ram E, Goldenberg I, KassifY, Segev A, Lavee J, Shlomo N, et al. Comparison of patients with multivessel disease treated at centers with and without on-site cardiac surgery. J Thorac Cardiovasc Surg. 2018;155(865-873):e3.

33. Meagher P, Adam M, Civitarese R, Bugyei-Twum A, Connelly KA. Heart failure with preserved ejection fraction in diabetes: mechanisms and management. Can J Cardiol. 2018;34:632-43.

34. Kragelund C, Snorgaard O, Køber L, Bengtsson B, Ottesen M, Højberg S, et al. Hyperinsulinaemia is associated with increased long-term mortality following acute myocardial infarction in non-diabetic patients. Eur Heart J. 2004:25:1891-7. 